\title{
O uso da pílula anticoncepcional de emergência: uma análise comparativa entre mulheres vivendo e não vivendo com HIVIAIDS.
}

\author{
Heidi M Sousa (IC), Regina M Barbosa (PQ)
}

\begin{abstract}
Resumo
Este estudo tem como propósito analisar o uso da pílula anticoncepcional de emergência (PAE) entre as mulheres vivendo com HIVIAids e os fatores associados ao seu uso, a partir de estudo comparativo com mulheres não vivendo com HIVIAids. Com base nos resultados, pode-se dizer que o uso da PAE é menor no primeiro grupo, especialmente entre aquelas com baixa escolaridade, mais velhas e sem parceiro.
\end{abstract}

Palavras Chave: Anticoncepção de emergência, Mulheres, HIVIAIDS.

\section{Introdução}

O uso de métodos contraceptivos cresceu bastante nas últimas décadas no Brasil. Entre os métodos contraceptivos existentes, o preservativo ganha destaque seguido da pílula e da laqueadura ${ }^{1}$. Apesar disso, cerca de $45 \%$ das gestações ocorrem de maneira não planejada no pais $^{2}$. A introdução da pílula anticoncepcional de emergência (PAE) na década de 90 possibilitou, pela primeira vez, prevenir a gravidez após uma relação sexual desprotegida. Se, segundo resultados da PNDS de 2006, ainda estamos longe do conhecimento e acesso universal à PAE, pouco sabemos de seu uso em contextos específicos, como aquele experimentado pelas mulheres vivendo com HIVIAids (MVHA).

A ênfase no uso do preservativo neste contexto pode tornar a PAE um instrumento importante para garantir às MVHA maior controle sobre a sua fecundidade. Diante desse cenário este estudo tem como propósito analisar o uso da PAE entre as mulheres vivendo com HIVIAids e não vivendo com HIVIAids (MNVHA).

\section{Resultados e Discussão}

Os dados analisados são provenientes do estudo GENIH, conduzido no município de São Paulo entre 2013 e 2014. A presente análise foi realizada a partir de uma amostra probabilística de 943 MVHA e 971 MNVHA, com idade entre 18 e 49 anos e foram usados testes estatísticos de associação e modelos de regressão logística.

Adotou-se como variável dependente o uso de PAE e como variáveis explicativas a idade, escolaridade, raça/cor, religião, situação conjugal, ocorrência de gestação e aborto provocado na vida, o tipo de serviço de saúde utilizado pela entrevistada. Para todos os testes estatísticos foram utilizados um nível de significância de 5\%. O software estatístico utilizado foi o SPSS 18.

O uso de PAE foi $27,6 \%$ entre as MVHA em contraposição a $42,1 \%$ entre às MNVHA. Os fatores associados ao uso de PAE em ambos os grupos são: idade, (uso maior entre aquelas com idade entre 18-24 e 25-34 anos); escolaridade (uso maior entre aquelas com ensino médio completo e ensino superior); e situação conjugal (entre as MVHA, o uso é maior entre aquelas que tem parceiro estável e moram junto com o parceiro, e entre as MNVHA as que não tem parceiro atual). Além dessas variáveis, para o grupo de MNVHA, outros fatores estão associados ao uso da PAE; seu uso é maior entre mulheres que já engravidaram $(O R=1,66)$ e relataram aborto provocado $(\mathrm{OR}=4,30)$.

\section{Conclusões}

O menor uso de PAE entre as MVHA, especialmente entre aquelas com baixa escolaridade, mais velhas e sem parceiro, aponta para dificuldades específicas de acesso dessa população ao método. Ao mesmo tempo, o fato de variáveis relacionadas à vida reprodutiva, como ter engravidado ou ter realizado aborto, não estarem associadas ao uso do método entre MVHA, nos faz pensar que a infecção pelo HIV confere importância a outras dimensões da vida dessas mulheres, que merecem ser melhor compreendidas em novos estudos.

\section{Agradecimentos}

Primeiramente agradeço à Profa . Regina Maria Barbosa do Núcleo de Estudos de População Elza Berquó (NEPO) pela oportunidade de participar desse projeto, pela orientação cuidadosa e dedicação durante esse trabalho. Agradeço também ao CNPQ, à FAPESP, ao NEPO, ao Serviço de Apoio ao Estudante pela bolsa de iniciação cientifica e à Unicamp pelas ferramentas utilizadas ao longo do percurso.

\footnotetext{
${ }^{1}$ Arilha, M.; Lapa, T.; Pisaneschi, T. 2010.

2 Leal, MC, 2012

${ }^{3}$ BRASIL. Ministério da Saúde.PNDS. 2006
} 